\title{
O trabalho em pequenas cidades do território do sisal
}

\author{
Edmar de Jesus Lobo Silva ${ }^{1}$; \\ Onildo Araujo ${ }^{2}$
}

1. Bolsista PROBIC/CNPq, Graduando em Geografia, Universidade Estadual de Feira de Santana, e-mail: edmarlobogeo@hotmail.com

2. Orientador, DCHF, Departamento de Ciências Humanas e Filosofia, Universidade Estadual de Feira de Santana, email: fssilvas@hotmail.com

PALAVRAS-CHAVE: pequenas cidades, trabalho, desenvolvimento e potencialidades.

\section{INTRODUÇÃO}

O tema, Trabalho nas Pequenas Cidades do Território do Sisal, que foi proposto no plano de trabalho que faz parte do trabalho do grupo de pesquisa em geografia e movimentos sociais, cujo titulo é "A dinâmica urbano-rural e a reorganização do espaço nas pequenas cidades do território do sisal no estado da Bahia-Brasil: da reestruturação da cadeia produtiva do sisal à consolidação do tecido associativo $(1990$ - 2014)." O plano de trabalho buscou caracterizar como se da, as relações de trabalho nas pequenas cidades, relações estas que nada mais é que dentre as possibilidades de emprego as atividades formais e informais que podem ser desenvolvidas pela população e a participação dos agentes produtores tanto do espaço urbano quanto do rural. Diante da analise dos dados coletados e da pesquisa desenvolvida que caracterizar o território também expondo os municípios em seus retrocessos e evolução no período estudado e demonstrado no decorre deste texto.

\section{METODOLOGIA}

Foi realizada uma investigação a partir do levantamento bibliográfico e elaborando referencial teórico, em seguida com o levantamento de dados sobre o trabalho nos municípios do Território do Sisal, disponíveis no Instituto Brasileiro de Geografia e Estatística (IBGE), Superintendência de Estudos do Estado da Bahia (SEI) e Organização Internacional do Trabalho (OIT) e a tabulação dos dados para a elaboração de tabelas e gráficos, mapas.

\section{Retrocessos e evoluções do trabalho no território do sisal de 1991 a 2015}

A dinâmica do território do sisal é notória, mas o que se percebe é que as cidades detêm nesse período desenvolvimento diferenciado e entre estas poucas se destacam pelo desenvolvimento econômico e geração de receitas própria, o que as tornaria menos dependentes de ações do governo federal, um dos retrocessos percebido durante a pesquisa.

Quanto à geração d emprego formal a tabela 1 a seguir apresenta o saldo referente ao ano de 2010, em que o território apresenta saldo total de 1.219 empregos gerados em todos os municípios. Estão representados na tabela atividades econômicos do território em que caracteriza o saldo positivo e negativo de cada município. Ainda nessa mesma tabela destaca se conceição do coité que apresentou apenas resultados positivos quanto à geração de emprego com 351 novas vagas enquanto Teofilândia 
destaca se de forma negativa com o saldo negativo de 36 vagas de emprego no ano de 2010.

Tabela 1- Saldo de emprego celetista, segundo atividade econômica, por município Território de Identidade Sisal, Bahia - 2010

\begin{tabular}{|c|c|c|c|c|c|c|c|c|}
\hline $\begin{array}{c}\text { Municípi } \\
0\end{array}$ & $\begin{array}{c}\text { Extrat } \\
\text { iva } \\
\text { Miner } \\
\text { al }\end{array}$ & $\begin{array}{c}\text { Indústria } \\
\text { de } \\
\text { Transforma } \\
\text { ção }\end{array}$ & $\begin{array}{c}\text { Serviço } \\
\text { s } \\
\text { Industri } \\
\text { ais de } \\
\text { Utilida } \\
\text { de } \\
\text { Pública }\end{array}$ & $\begin{array}{l}\text { Constru } \\
\text { ção Civil }\end{array}$ & $\begin{array}{l}\text { Comér } \\
\text { cio }\end{array}$ & $\begin{array}{l}\text { Servi } \\
\text { ços }\end{array}$ & $\begin{array}{l}\text { Administ } \\
\text { ração } \\
\text { Pública }\end{array}$ & $\begin{array}{c}\text { Agropecu } \\
\text { ária, } \\
\text { Extrativa } \\
\text { Vegetal, } \\
\text { Caça e } \\
\text { Pesca }\end{array}$ \\
\hline Araci & 0 & 3 & 0 & 156 & 34 & 11 & 0 & -6 \\
\hline
\end{tabular}

\begin{tabular}{lrrrrrrrrr|} 
Barrocas & -5 & -1 & 0 & 23 & -21 & 2 & 0 & 0 & -2 \\
\hline Biritinga & 0 & -1 & 0 & -15 & 12 & 0 & 0 & 7 & 3 \\
\hline Candeal & 0 & -5 & 0 & 0 & 5 & 3 & 0 & 0 & 3 \\
\hline Cansanç & 0 & 0 & 0 & -2 & 10 & 1 & 0 & 0 & 9
\end{tabular}

ão

$\begin{array}{llllllllll}\text { Conceiç } & 0 & 178 & 0 & 49 & 77 & 34 & 0 & 13 & 351\end{array}$

ão do

Coité

\begin{tabular}{|c|c|c|c|c|c|c|c|c|c|}
\hline Ichu & 0 & 12 & 0 & -7 & -1 & 0 & 0 & 0 & 4 \\
\hline Itiúba & 1 & -8 & 0 & 0 & 19 & 2 & 0 & 4 & 18 \\
\hline Lamarão & 0 & 0 & 2 & 0 & 2 & 0 & 0 & 1 & 5 \\
\hline Monte & 0 & -2 & 0 & 0 & 45 & 1 & 0 & 4 & 48 \\
\hline
\end{tabular}

\begin{tabular}{llllllllll}
$\begin{array}{l}\text { Monte } \\
\text { Santo }\end{array}$ & 0 & -2 & 0 & 0 & 45 & 1 & 0 & 4 & 48 \\
\hline Nordesti & 2 & 0 & 0 & 1 & 10 & 4 & 0 & 0 & 17
\end{tabular}

$\begin{array}{llllllllll}\text { na } & 0 & 0 & 0 & 0 & 13 & 10 & 0 & 3\end{array}$

das

$\begin{array}{llllllllll}\text { Quijingu } & 0 & 0 & 0 & -16 & 2 & 1 & 0 & -2 & -15\end{array}$

e

$\begin{array}{llllllllll}\text { Retirolâ } & 3 & 60 & 0 & 0 & -4 & 1 & 0 & -2 & 58\end{array}$

ncia

\begin{tabular}{lrrrrrrrrr} 
Santaluz & 9 & 117 & 0 & -35 & 17 & -1 & 0 & 2 & 109 \\
\hline São & 0 & -2 & 0 & 2 & 5 & 1 & 0 & 0 & 6
\end{tabular}

Domingo

S

$\begin{array}{lrrrrrrrrr}\text { Serrinha } & -114 & 227 & 1 & -180 & 114 & 101 & 39 & 1 & 189 \\ \text { Teofilân } & 0 & -8 & 0 & 0 & -2 & -26 & 0 & -36\end{array}$

dia

Tucano

\begin{tabular}{lrrrrrrrrr} 
Valente & -1 & -3 & 0 & -1 & 42 & 4 & 0 & 1 & 42 \\
\hline Total & 0 & 64 & 0 & 3 & 36 & 85 & 0 & -2 & 186 \\
\hline & -105 & 631 & 3 & -22 & $\mathbf{4 1 5}$ & $\mathbf{2 3 4}$ & $\mathbf{3 9}$ & $\mathbf{2 4}$ & $\mathbf{1 . 2 1 9}$
\end{tabular}

Fonte: Cadastro Geral de Empregados e Desempregados (CAGED), 2010. Dados sistematizados pela SEI/DIPEQ/COPES, 2012.

A pesquisa mostra evoluções gradativas em ambas as cidades do território no que se refere ao IDH e como foi essa escalada, partindo de índices de desenvolvimento alarmantes à chegada em índices aceitáveis na maioria dos municípios. Sempre colocando que enquanto o trabalho em suas esferas não teve muito destaque no território mas quanto a situação social, os municípios apresentarão índices favoráveis devido à interferência do estado. 
Os impactos das políticas públicas, principalmente a educacional e a de renda e combate à pobreza, provocaram uma substancial melhoria nas condições de vida capitadas pelo indicador. As pequenas cidades também apresentam os comportamentos das gerações contemporâneas, como por exemplo, os movimentos migratórios agindo sobre uma dinâmica de tempo e espaço nova que contribui para a dinâmica populacional e o movimento pendular, que dinamiza bastante o espaço.

Percebe-se que essas cidades possuem vulnerabilidade fiscal, com baixa capacidade de receitas próprias, o que as torna mais vinculadas aos programas sociais do governo federal, principalmente para custeio de educação, saúde, saneamento básico e investimentos em infraestrutura. As receitas próprias são insuficientes para a execução de políticas públicas que possam melhorar a qualidade de vida da população.

No gráfico 1 percebe se que as receitas próprias dos municípios do território no ano de 2015 representam os resultados obtidos nos outros dados em que demonstram queda nos rendimentos e geração de renda pelo trabalho em contrapartida de uma maior dependência das cidades de repasses do governo federal para sua manutenção enquanto cidade.

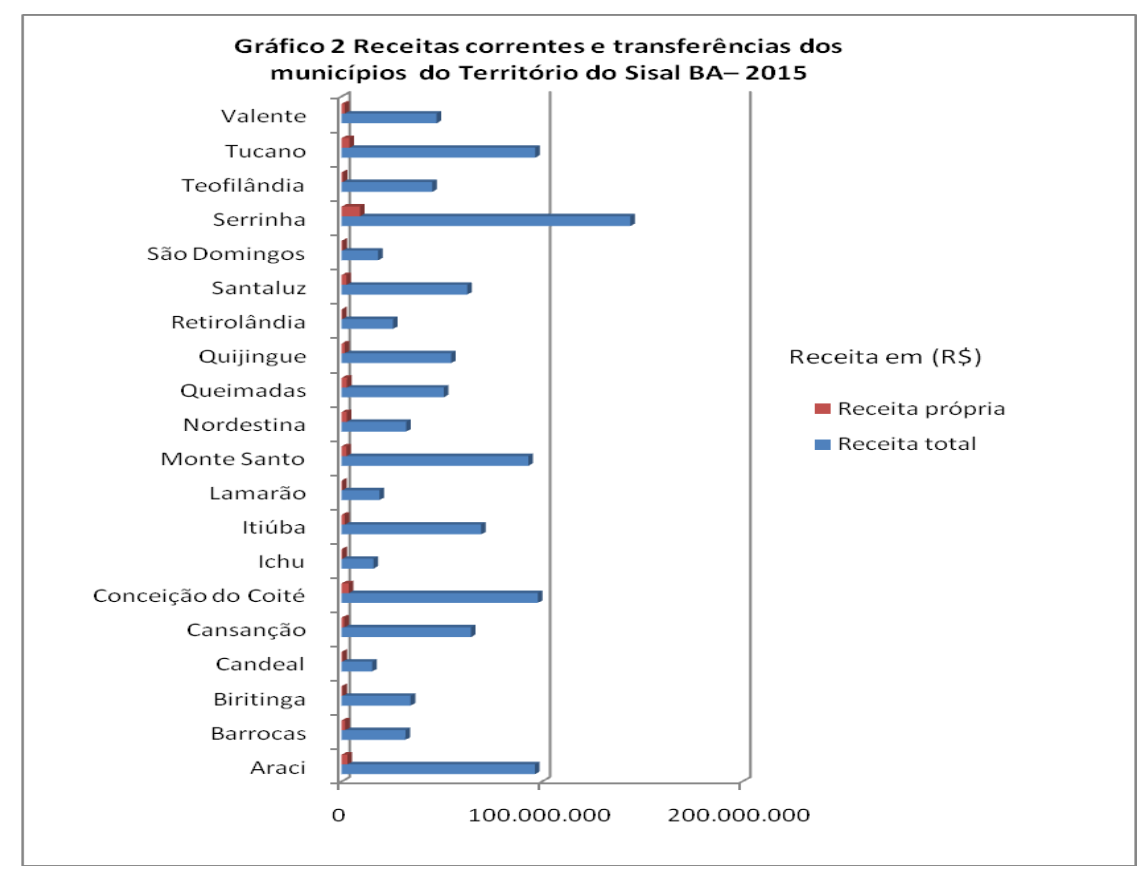

Fontes: Instituto de Pesquisa Econômica Aplicada, Fundação João Pinheiro e Instituto Brasileiro de Geografia e Estatística (2013).

\section{CONCLUSÃO}

Analisando dados sociais econômicos e demográficos ligados diretamente à variável trabalho de tabelas com os municípios do território de identidade do Sisal nos censos de 1991, 2000, 2010 e 2015. Percebe-se que, a influência do trabalho para a arrecadação e o funcionamento das cidades demonstra as vulnerabilidades dos municípios, por incapacidade de criar receitas próprias, para que possa ser capaz custear seus gastos com educação, saúde, saneamento básico e investimentos em infraestrutura. Dentro da perspectiva de que um município com uma situação fiscal favorável deve 
apresentar um total de receita própria decorrente da arrecadação municipal (ISS; IPTU; ITBI) acima de 30,0\% da receita total, percebe-se então que todos os municípios do território se encontram muito abaixo desse percentual. Ao passo que as receitas geradas pelo município não contribuem com a implantação de políticas publicas voltadas ao bem estar da população, fica bem visível a necessidade de repasses de verba e investimentos de ordem federal. Pelo dinamismo percebido no território quanto à capacidade de produção e reprodução de capital por meio de produção de bens e serviços, o trabalho deve ser mais observado pela sua capacidade de transformação social em suas diferentes esferas.

\section{REFERENCIAS}

ANTONELLO, Ideni Teresina .Reestruturação Produtiva no espaço rural: forjando mutações nas relações urbano-rurais. Dossiê: RELAÇÕES CAMPO-CIDADE TEMAS \& MATIZES - Nº 16 - SEGUNDO SEMESTRE DE 2009. p 24-51.

MALTHUS, Thomas Robert. Princípios de Economia Política e Considerações Sobre sua Aplicação Prática. São Paulo: Nova Cultural, 1996.

SCHNEIDER, Sérgio. Teoria social, agricultura familiar e pluriatividade. Rev. bras. Ci. Soc., Fev 2003, vol.18, no.51, p.99-122.

KAGEYAMA, Angela. Desenvolvimento Rural: Conceito e Medida. Cadernos de Ciência \& Tecnologia, Brasília, v. 21, n. 3, p. 379-408, set./dez. 2004.

GRAZIANO, da Silva. Oficina de Atualização Temática. Ocupações Rurais Não agrícolas. O Novo Rural Brasileiro. Projeto Rurbano apresentado à FAPESP. 1998.

MENDONÇA, Marcelo Rodrigues; Trabalho e Dinâmicas Territoriais no Campo: os Povos Cerradeiros na Luta por um Território Livre.Revista Pegada - vol. 12 n.2 23 dezembro/2011.

REIS, Jair Teixeira dos.História do Trabalho e seu conceito. Disponível na Internet http://blog.newtonpaiva.br/direito/wp-content/uploads/2012/08. Acesso 2016.

Resende. Tomaz de Aquino. Terceiro Setor, ONGs e Institutoshttp://www.fundata.org.br/Artigo.Cefeis TERCEIR SETOR, ongs.pdf acesso 2016

THOMAZ JÚNIOR, Antonio; Por uma Geografia do Trabalho. São Paulo: [s.n], 2009.

VILELA, Meire; Elaine. Migrações e trabalho no Brasil Fatores étnico-nacionais e raciais. Revista brasileira de ciências sociais - VOL. $30 \mathrm{~N}^{\circ}$ 87, 2015.

Estatísticas dos Municípios Baianos [recurso eletrônico] / Superintendência de Estudos Econômicos e Sociais da Bahia. v. 1 (2000 - ). - Salvador: SEI, 2012.http://www.sei.ba.gov.br. 